\title{
Stability Assessment of Dangerous Rock Mass of an Overhanging Slope in Puerdu Town, Southwestern China
}

\author{
Wen-Lian Liu,, Jia-Xing Dong $\mathbb{D}^{2,3}$ Su-Gang Sui, ${ }^{1,2}$ Han-Hua Xu $\mathbb{D}^{1,2}$ Run-Xue Yang, ${ }^{3}$ \\ and Zhen-Luo Shen ${ }^{3}$ \\ ${ }^{1}$ Kunming Prospecting Design Institute of China Nonferrous Metals Industry Co., Ltd., Kunming 650051, Yunnan, China \\ ${ }^{2}$ Yunnan Key Laboratory of Geotechnical Engineering and Geohazards, Kunming 650051, Yunnan, China \\ ${ }^{3}$ Faculty of Electric Power Engineering, Kunming University of Science and Technology, Kunming 650500, Yunnan, China
}

Correspondence should be addressed to Jia-Xing Dong; dong1986@kust.edu.cn and Han-Hua Xu; 724767210@qq.com

Received 23 April 2021; Accepted 1 June 2021; Published 6 July 2021

Academic Editor: Faming Huang

Copyright (c) 2021 Wen-Lian Liu et al. This is an open access article distributed under the Creative Commons Attribution License, which permits unrestricted use, distribution, and reproduction in any medium, provided the original work is properly cited.

Dangerous rock mass in the overhanging slope of Puerdu town has good free-face condition, high position, and great potential energy, identification and stability evaluation of which is a difficult problem in the disaster prevention. In this paper, the limit equilibrium method was used to evaluate the dangerous rock mass stability in the overhanging slope. Firstly, geomorphic characteristics and the distribution of dangerous rock mass are determined by the field geological survey. Secondly, six dangerous rock masses which may cause more threat are studied, with defining their failure modes and characteristic parameters. Finally, a simplified geological model is established, the stability coefficient of dangerous rock mass under different conditions is calculated by the limit equilibrium method, at the same time, stability analysis of dangerous rock mass is carried out based on the stereographic projection, and the hazard probability is estimated by the empirical formula. Results show that joints obviously developed in the dangerous rock mass of $W 1, W 2, W 3, W 4, W 5$, and $W 6$, with falling-type and toppling-type failure modes. In the natural condition, the dangerous rock mass is understable and unstable under the rainstorm and earthquake conditions. Consequently, rainstorm and earthquake are the key triggering factors of the instability and collapse of dangerous rock mass.

\section{Introduction}

Rock mass collapse is a common geological disaster in mountainous areas. Most dangerous rock masses exist on the overhanging slope or steep cliff, and such rock masses are divided by multiple structural planes and have poor stability [1]. In June 2006, the overhanging slope of a highway in the southeastern Qinghai-Tibet Plateau, China, collapsed after more than ten consecutive days of rainstorm, and the loose dangerous rock mass fell about $400 \mathrm{~m}^{3}$. A large number of rock mass tumbled down the slope, and some houses at the foot of the slope were destroyed, forming a disaster. Meanwhile, it is also a serious threat to the highway project and the production and life of local residents, with extremely serious consequences [2]. In August 2017, a magnitude 7.0 earthquake occurred in Jiuzhaigou, Sichuan, China. Due to the impact of the earthquake on the rock mass cracking damage, a large number of high or very high collapse hazards existed in the core scenic spots of Jiuzhaigou, which seriously threatened the life and property safety of tourists and local residents [3].

The stability evaluation of dangerous rock mass can be used as the basis for the design of support structure to prevent and control the disaster of dangerous rock mass scientifically and effectively. The Bishop method [4] considers the lateral force of the soil strip, but does not take into account the horizontal force; on the other hand, the tangent force is assumed to be equal, so the analysis results have certain limitations. Mithun et al. [5] used remote sensing technology to monitor glacier changes on the Bhutanese Himalayan Plateau and evaluate the stability of dangerous rock mass. Li et al. [6] also proposed that the unstable failure of dangerous rocks has obvious spatial characteristics. When Wang et al. [7] studied the stability of Jianchuandong 
dangerous rock mass in the Three Gorges Reservoir area, they proposed that the instability mechanism was that the weight of the upper rock mass and the periodic change of the reservoir water level led to the weakening of the foundation rock mass and the increasing damage, which eventually led to the collapse of the bedrock, and carried out stability analysis on it. Li [8] proposed the collapse prevention method by strengthening the dangerous rock mass to slow down the development of unloading cracks. In a general way, the classification of deformation and failure modes is a necessary step for the stability analysis of the dangerous rock mass. According to the geological conditions of the study area. Dong et al. [9] classified the hazard soruces in surrounding slope of a hrdropower station into isolated stone, dangerous rock, dangerous rock mass and high position covering layer. Kuang [10] comprehensively considered the failure mechanism and stress state of unstable dangerous rock mass and classified the collapse types into shear-fall, tension-break, fall-fall, tipping-collapse, crushing and caving, etc. Huang and Deng [11] divided the dangerous rock mass into seven types according to the instability mechanism, including slope attachment type, suspension type, isolated type, slab crack type, cataclastic type, block type, and soft foundation type. When Zhang et al. [12] studied deformation and failure characteristics of Lianziya dangerous rock mass, they summarized 8 deformation and failure modes.

The stability evaluation of dangerous rock mass is mainly carried out from qualitative and quantitative methods. $\mathrm{Li}$ et al. [13] used the stereographic projection method and limit equilibrium method to analyze the stability of slipping Hesonglou dangerous rock mass in Hubei province of China. On this basis, the measure is put forward. Based on the key block theory, Zhang et al. [14] proposed the stability probobility assessment method of the cataclastic rock masses. Tao et al. [15] analyzed stability of a cutting rock slope of a hydropower project located on Dadu river in Sichuan province of China using the SSPC method. Based on the limit equilibrium method and fracture mechanics theory, Gong [16] generalized the mechanical model of dangerous rocks in the Three Gorges Reservoir area, analyzed the maximum circumference stress fracture criterion and maximum shear stress fracture criterion, and deduced the stability coefficient expression of dangerous rocks. Xiao [17] used the limit equilibrium method to analyze the stability of dangerous rock mass in the Wanzhou Taibai rock slope and studied the influence of crack angle, vertical seismic force, and horizontal seismic force on the safety factor of dangerous rock mass. Chen [18] used the limit equilibrium theory to calculate and analyze the stability of slump-type dangerous rock mass in the Shouli Mountain, Wanzhou. When earthquakes and rainfall acted together, the decisive factor for the stability of dangerous rock mass was mainly horizontal seismic force. Li et al. [19] took the dangerous rock mass in a limestone area and granite area of Baoxing County, Yaan City, the "Wenchuan" earthquake zone, as the research object and made stability evaluation and analysis of the dangerous rock mass. The results showed the simplicity of the rigid body limit equilibrium method in the stability analysis of the dangerous rock mass. Zhao and $\mathrm{Bu}$ [20] used the block limit equilibrium method to calculate the safety factor and sliding direction of dangerous rock mass and analyze its stability. By combining the Monte Carlo method and the block limit equilibrium method, the function of stability reliability was proposed, and the reliability index and instability probability were obtained. Taking Baiyanshan dangerous rock mass as the object, Liu et al. [21] used the limit equilibrium method to carry out quantitative checking calculation on the stability of the dangerous rock mass and comprehensively analyzed and evaluated the development characteristics and stability of the dangerous rock mass in Guilin.

The dangerous rock mass of the overhanging slope in Puerdu Town, Yanjin County, Zhaotong City, Yunnan Province, China, is a riparian slope area with a canyon landform that is intersected with structural erosion and river erosion. According to the terrain, the slope has already had the condition of collapse. Once the dangerous rock collapses, it will bring a great threat to the lives and property safety of the villagers. Therefore, the stability evaluation of dangerous rock mass in the study area will be beneficial to the geological disaster prevention and control planning of Yanjin County, and it provides the corresponding theoretical basis for disaster prevention and control, which has a very important practical significance. At present, there are many studies on the stability analysis of dangerous rock mass, but the stability evaluation of overhanging slope dangerous rock mass in mountainous areas is less. Based on the limit equilibrium method, this paper calculates the stability coefficient and hazard probability of the falling-type and tipping-type dangerous rock mass in the study area under different working conditions and evaluates the stability of six groups of dangerous rock mass with greater threat in the study area.

\section{Geological Environment Background}

2.1. Geographical Position. Puerdu town is located at the confluence of the Chuansi River, the Shangqing River, and the first-class tributary of the Jinsha River. The geographical coordinates are $104^{\circ} 10^{\prime} \mathrm{E}, 28^{\circ} 14^{\prime} \mathrm{N}$. The straight-line distance from Zhaotong is about $110 \mathrm{~km}$ and from Yanjing is about $25 \mathrm{~km}$. The location of the study area is shown in Figures 1 and 2.

2.2. Meteorological Hydrology. The average annual temperature in the region is $17^{\circ} \mathrm{C}$, and the average annual rainfall in the area is $1226.2 \mathrm{~mm}$. Rainfall is concentrated in June, July, August, and September, accounting for $82 \%$ of the annual precipitation. The average annual evaporation is $1083.5 \mathrm{~mm}$, and the relative humidity is $81 \%$.

2.3. Topographic Features. The topography and geomorphology of Puerdu town are mainly characterized by the flow geomorphology controlled by the geological structure. The basic geomorphologic units are mountains and canyons, in addition to the gentle slope geomorphology developed along the sedimentary rock level. Deep valley in the area is mainly 


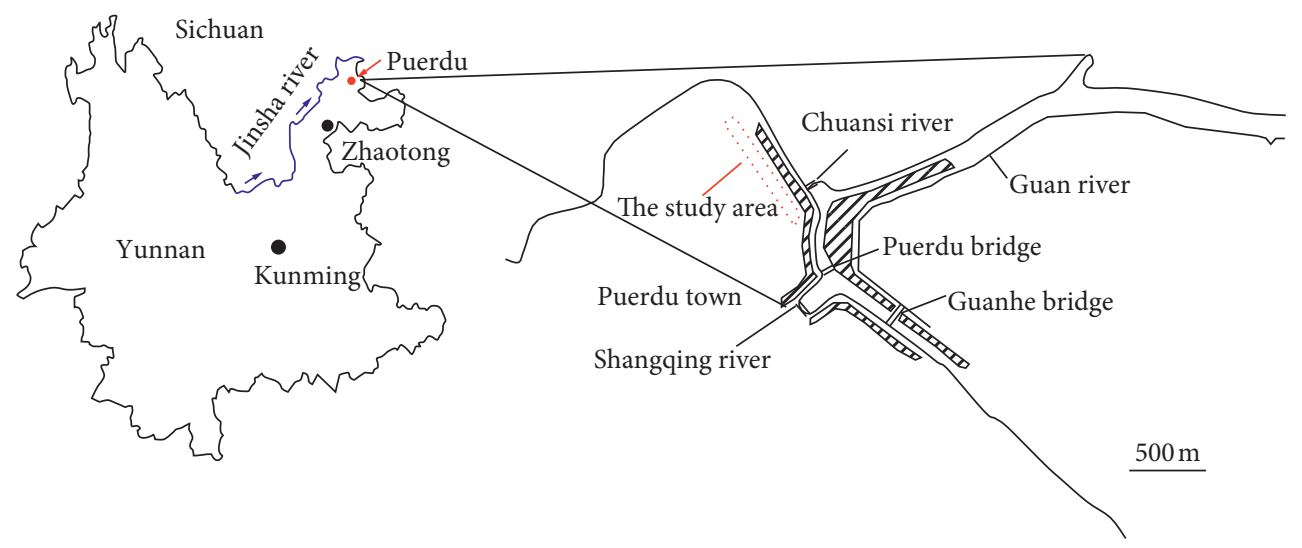

(a)

(b)

Figure 1: Location of the study area.

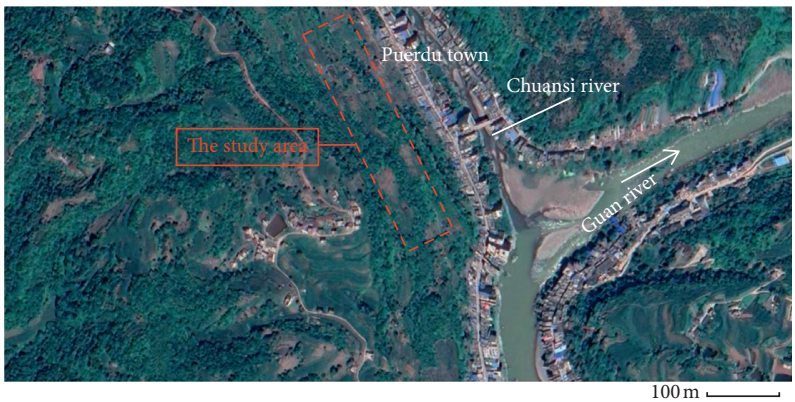

FIgURE 2: Location of the study area (satellite camera).

manifested as $\mathrm{V}$-type valley and steep valley slope, slope is generally above 30 , and vegetation coverage is high.

2.4. Stratigraphic Lithology. On the basis of field investigation and exploration, the stratigraphic lithology of this area is mainly composed of the quaternary residual slope layer $\left(Q_{4}{ }^{\mathrm{el}+\mathrm{dl}}\right)$ containing gravel silty clay, block stone soil, gravel soil, and pebble, and the underlying bedrock is the Jurassic Middle Series Shaximiao formation (J2S), including brown, purple gray sandstone interbedded with purplish red mudstone, silty mudstone, and argillaceous siltstone.

\section{Engineering Geological Features of Dangerous Rock Areas}

The occurrence of collapse is closely related to the scour cutting of the Guanhe River and Chuansi River and also to the slope rock mass structure. The regional geological history study shows that there is a belt distribution under the cliff, with a length of $100-1000 \mathrm{~m}$, and a large collapse accumulation layer with a thickness of 10-20 m, which is a largescale collapse in the Middle and Late Pleistocene. The scale of modern collapse is small, but the harm is serious. The dangerous rocks in this area have various forms, and their basic geometric forms are massive, columnar, plate-shaped, and inverted-cut cone-shaped. Other forms include arch bridge and cantilever. According to their deformation characteristics and failure forms, dangerous rock collapse can be divided into collapse accumulation area and cliff dangerous rock area. According to the topographic features, the study area is divided into four levels of dangerous rocks from bottom to top, and each level of dangerous rocks is further divided into three microlandforms, including the upper gentle slope area, the steep cliff area, and the lower slope area. The landform map of the collapse accumulation area and cliff dangerous rock area is shown in Figure 3.

Grade 1 dangerous rock upper gentle slope area: it is located in the upper part of a steep cliff, the terrain slope is $20-34^{\circ}$, the average slope is $29^{\circ}$, the elevation difference is $51-104 \mathrm{~m}$, and the average is $68 \mathrm{~m}$; steep cliff area: the length of the cliff zone is $984 \mathrm{~m}$, the slope of the cliff is $\mathrm{N} 62^{\circ} \mathrm{W}$, the height difference is $8-25 \mathrm{~m}$, most of the steep cliffs are upright, and some of the steep cliffs' angle is between 70 and $90^{\circ}$. The main slope area at the bottom of the Grade 1 dangerous rock steep cliff: from the lower part to the upper part of the Chuansi River, the elevation difference increases gradually from $58 \mathrm{~m}$ to $102 \mathrm{~m}$. The topographic slope also increases gradually from the lower part to the upper part of the Chuansi River, from $26^{\circ}$ to $38^{\circ}$. In the middle part of the country, the topography is mostly step-shaped due to the residential area cutting slope construction. The cut slope height is $10-15 \mathrm{~m}$, and the cut slope degree is mostly in an upright state. 


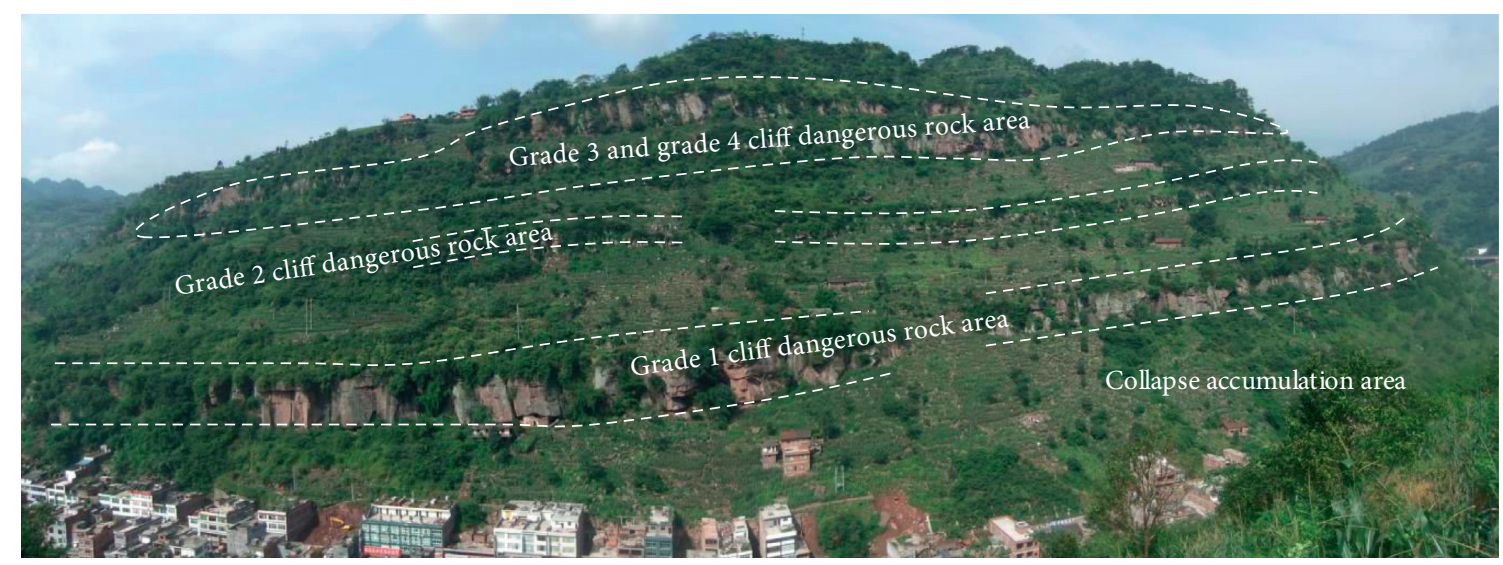

FIGURE 3: Geomorphologic map of the collapse and accumulation area and cliff dangerous rock area.

Grade 2 dangerous rock upper gentle slope area: it is located in the upper part of the secondary steep cliff, with a topographic slope of $25-34^{\circ}$, an average slope of $33^{\circ}$, an elevation difference of $30-50 \mathrm{~m}$, and an average of $39 \mathrm{~m}$; steep cliff area: the distribution is discontinuous, the length of the cliff is $497 \mathrm{~m}$, the cliff line is $S 63^{\circ} \mathrm{E}$, the height difference is 6-13 m, most of the cliffs are upright, and some of the cliffs' angle is between 70 and $90^{\circ}$. The lower slope of the grade 2 dangerous cliff is the upper gentle slope of the grade 1 steep cliff.

Most of the grade 3 and grade 4 dangerous rocks are connected together. The terrain is relatively slow from the upper part to the gentle slope area of the mountain top, and the slope of the terrain is $20-25^{\circ}$. The length of the steep cliff zone is $820 \mathrm{~m}$, the cliff direction is $\mathrm{N} 62^{\circ} \mathrm{W}$, and the height difference is $15-43 \mathrm{~m}$. The lower slope of the grade 3 and grade 4 dangerous rocks is the upper gentle slope of the grade 2 dangerous rocks.

\subsection{Engineering Geological Characteristics in the Collapse} Accumulation Area. The collapse accumulation area is located on the slope zone on the right bank of the Chuansi River. The slope and the steep cliff are in abrupt contact. The overall trend of the slope is $\mathrm{N} 25^{\circ}-30^{\circ} \mathrm{W}$ and tends to NE. Generally belonging to the middle slope, due to artificial slope cutting, the terrain slope is almost verticle, the height of cutting slopes is $8-10 \mathrm{~m}$, with a height of $15 \mathrm{~m}$ in some areas. The collapse accumulation body has a transverse length of 750-m, a longitudinal length of $115-320 \mathrm{~m}$, a thickness of 2.3-18.2 m, an average thickness of $8 \mathrm{~m}$, an area of $111,660 \mathrm{~m}^{2}$, and a volume of $893,280 \mathrm{~m}^{3}$. It is a large collapse accumulation body with a large scale of collapse points.

\subsection{Engineering Geological Characteristics in the Steep Cliff} Dangerous Rock Area. The steep cliff dangerous rock area is located in the high-steep slope zone on the right bank of the Chuansi River. The high-steep slope can be divided into two sections. The upper section is the steep cliff, and the lower section is the moderate gentle slope. The slope height is mostly 100-200 m. Most of the cliff walls are in the upright state, the rock walls are smooth, and the dangerous rocks are well developed. The first level of the cliff dangerous rock area is $8-68 \mathrm{~m}$ away from the residential area, and the cliff dangerous rock belt is $976 \mathrm{~m}$ long. The strike of the wall is $\mathrm{S} 44^{\circ} \mathrm{E}$ from the starting point to $350 \mathrm{~m}$, from $400 \mathrm{~m}$ to $976 \mathrm{~m}$, it is $S 44^{\circ} \mathrm{E}$ from 400 to $976 \mathrm{~m}$, and it breaks off at $350 \mathrm{~m}-400 \mathrm{~m}$, and the height difference is $8-25 \mathrm{~m}$. Most of the cliffs are upright, and part of the cliff angle is between 70 and $90^{\circ}$. Joints cut the rock mass into blocks with different volumes of about $100-500 \mathrm{~m}^{3}$, and most of them are small collapses. In the distribution area of the steep cliff, there are many sections of soft rock weathering and denudation that have formed continuous cavities, the cavity rate is about $68 \%$, and the cavity volume is mostly between 70 and $220 \mathrm{~m}^{3}$. The lithologic composition of the dangerous rock mass is mainly the Middle Jurassic Shaximiao Formation (J2S) sandstone, argillaceous siltstone, silty mudstone, mudstone, etc.

In a word, dangerous rock mass will be transformed into an unstable state under the combined action of self-weight, fissure water pressure (natural state), rainstorm, earthquake force, and other factors.

3.3. Characteristics of Dangerous Rocks. After the field investigation of $W 1, W 2, W 3, W 4, W 5$, and $W 6$, the basic characteristics of the dangerous rock mass are shown in Table 1.

The photographs of $W 1, W 2, W 3, W 4, W 5$, and $W 6$ fields are shown in Figure 4.

\section{Analysis of the Formation Mechanism and Cause in Dangerous Rock Mass}

Through geological survey, it is concluded that the steep cliff dangerous rock area is located in the high-steep slope zone on the right bank of the Chuansi River, and the slope height is mostly $100-200 \mathrm{~m}$. The unloaded rebound of dangerous rock mass, the deformation and failure of the slope, and the formation and development of dangerous rock mass are very favorable because of the good hanging conditions. The rock mass structure of the steep slope provides the material 
TABLE 1: Basic parameters of the dangerous rock mass.

\begin{tabular}{|c|c|c|c|c|c|c|}
\hline Characteristic parameters & $W 1$ & $W 2$ & W3 & $W 4$ & W5 & W6 \\
\hline The height of the dangerous rock mass $(\mathrm{m})$ & 5.0 & 23.0 & 2.0 & 17.0 & 18.0 & 17.0 \\
\hline The length of the dangerous rock mass (m) & 32.7 & 23.0 & 20.0 & 24.0 & 23.0 & 30.0 \\
\hline The thickness of the dangerous rock mass $(\mathrm{m})$ & 4.0 & 8.0 & 7.0 & 6.0 & 8.0 & 5.0 \\
\hline Crack depth $(\mathrm{m})$ & 4.7 & 14.0 & 1.7 & 6.0 & 10.0 & 5.0 \\
\hline Dangerous rock mass volume $\left(\mathrm{m}^{3}\right)$ & 654.0 & 4232.0 & 280.0 & 2448.0 & 3312.0 & 2550.0 \\
\hline Weight $(\mathrm{kg})$ & 1654.6 & $10,706.5$ & 708.0 & 6192.0 & 8378.9 & 6450.0 \\
\hline
\end{tabular}

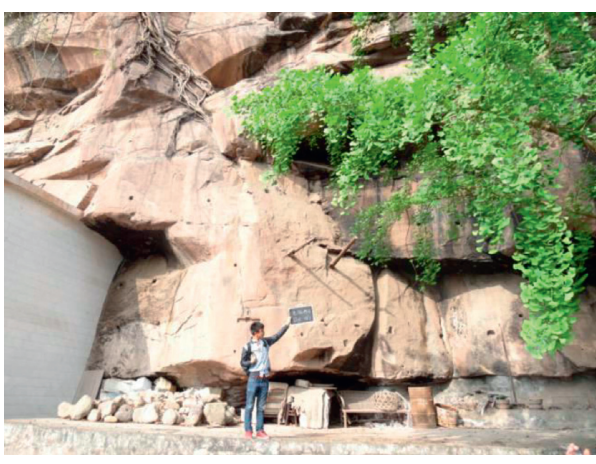

(a)

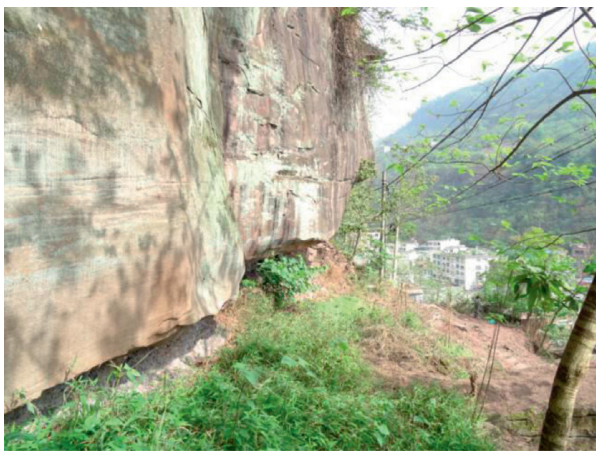

(c)

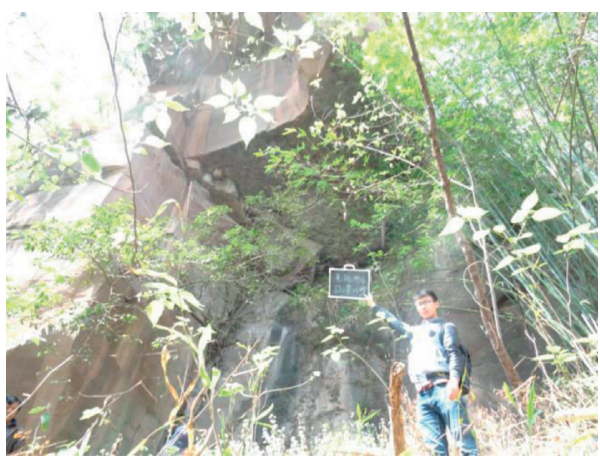

(e)

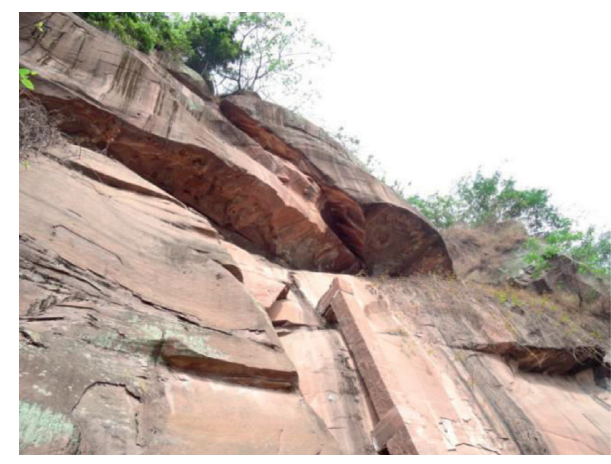

(b)

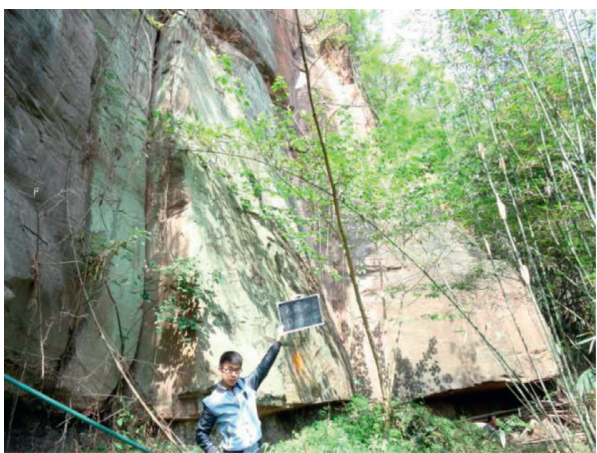

(d)

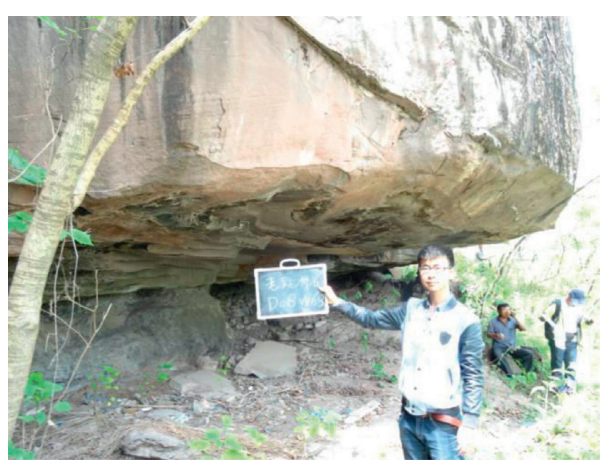

(f)

FiguRe 4: Photographs of dangerous rocks. (a) W1 dangerous rock mass. (b) W2 dangerous rock mass. (c) W3 dangerous rock mass. (d) W4 dangerous rock mass. (e) W5 dangerous rock mass. (f) W6 dangerous rock mass.

foundation for the formation of the dangerous rock, especially the interbedded sand and mudstone of the Middle Jurassic Shaximiao (J2S) Formation. The upper section of the slope is covered with sandstone, and the mudstone is under it, forming the step-like suspended slope with steep and slow phases. The sandstone layer is prone to brittle fracture, and the mudstone layer is prone to plastic deformation, which aggravates the deformation and failure of the whole rock mass.

Comprehensive analysis shows that the cutting and separation of the joints is the internal reason for the formation of dangerous rock mass in the study area. The rock 
blocks were formed with the intersecting of joints. In addition, under the action of hydrostatic pressure, water infiltrating into the fissure further promotes the fissure expansion, and the infiltration and immersion reduce the strength of the soft base of mudstone, strengthen the weathering effect, and intensify the plastic flow deformation. Meanwhile, they also increase the sliding force of dangerous rock mass and accelerate the formation of dangerous rocks.

Combined with the studies of many scholars on the instability failure modes of dangerous rock mass, it is concluded that the instability of dangerous rock mass of the overhanging slope in the study area is mainly falling type and tipping type, and its collapse formation mode is shown in Figure 5.

As shown in Figure 5, because the upper part of the cliff is hard and the lower part is soft, the mud layer in contact with the main slope begins to disintegrate under the action of pore water, the mudstone cavity appears, and the upper rock mass is unstable, resulting in the collapse of the dangerous rock body along the unloading joint.

\section{Stability Analysis of Dangerous Rock Mass}

5.1. Stability Analysis of Dangerous Rock Mass Based on the Stereographic Projection. The stability of the rock slope by the stereographic projection is based on the rigid assumption. The internal strain of the block is not considered; only the effect of sliding force and antisliding force of the block is considered. Through the stereographic projection, the structure surface and slope surface are projected to the plane, and the stability of the slope is evaluated. The basic attitude of the dangerous rock mass is shown in Table 2, and the stereographic projection is shown in Figure 6.

The dangerous rock mass was analyzed according to the stereographic projection, and the results are as follows:

In Figure 6(a), the angle between the slope surface and dip direction of the rock layer is $22^{\circ}$, with a similar dip direction, which is generally an unfavorable combination slope. There is little difference between the attitudes of $J 1$ and $b$, both of $J 1$ and $b$ have a steep dip. Line represents $J 2$ intersects with the layer as an unfavorable combination with the slope surface.Under the condition of "cavity" in the underlying mudstone, it is easy to cause the upper dangerous rock mass to "falling-type" failure.

In Figure 6(b), the angle between the slope surface and dip direction of the rock layer is $22^{\circ}$, with a similar dip direction, which is generally an unfavorable combination slope. The combination intersection of $J 1, J 2$, and st with the slope surface is unfavorable. Under the condition of "cavity" in the underlying mudstone, it is easy to cause the upper dangerous rock mass to "tipping-type" failure.

In Figure 6(c), the angle between the slope surface and dip direction of the rock layer is $7^{\circ}$, with a similar dip direction, which is generally an unfavorable combination slope. The combination intersection of $J 1, J 2$, and st with the slope surface is unfavorable. Under the condition of "cavity" in the underlying mudstone, it is easy to cause the upper dangerous rock mass to "fallingtype" failure.

In Figure 6(d), the angle between the slope surface and dip direction of the rock layer is $8^{\circ}$, with a similar dip direction, which is generally an unfavorable combination slope. The combination intersection of $J 1, J 2$, and st with the slope surface is unfavorable. $J 1$ and $J 2$ are rocks with cutting steep cliffs. Under the condition of "cavity" in the underlying mudstone, it is easy to cause the upper dangerous rock mass to "falling-type" failure. Similarly, stability and failure modes of W5 and W6 can be analyzed based on Figures 6(e) and 6(f).

5.2. Establishment of the Geological Model. Stability evaluation of dangerous rock mass is the foundation of the risk evaluation of dangerous rock mass. We analyzed the combination relationship of joints developed in dangerous rock mass, the degree of tension and closure, penetration, collapse direction of dangerous rock mass, and other factors. According to the field survey, six sections were selected to study the dangerous rock mass, and a generalized geological model was established according to the method proposed by Zhang et al. [21] and Doug Stead et al. [22].They are numbered $W 1, W 2, W 3, W 4, W 5$, and $W 6$; among them, the failure mode of $W 1, W 3, W 4$, and $W 6$ is falling type. On the contrary, $W 2$ and $W 5$ are the tippingtype dangerous rock mass [24]. Their geological profiles are shown in Figures 7-12, respectively.

\subsection{Stability Calculation}

5.3.1. Calculation Method. The dangerous rock mass in the study area is divided into two categories, falling-type dangerous rock mass and tipping-type dangerous rock mass. This paper adopts the calculation model proposed by Chen et al. $[25,26]$ similar to the project. The calculation models and main formulas of falling-type and tipping-type dangerous rocks are as follows. The schematic diagram of the falling type is shown in Figure 13, and the schematic diagram of the tipping type is shown in Figure 14.

Normal force:

$$
N=W \cos \beta-P \sin \beta .
$$

Tangential force:

$$
\begin{aligned}
T & =W \sin \beta+P \cos \beta, \\
\sigma & =\frac{N}{H / \sin \beta}, \\
\tau & =\frac{T}{H / \sin \beta}, \\
\tau_{f} & =\sigma \tan \phi+c,
\end{aligned}
$$




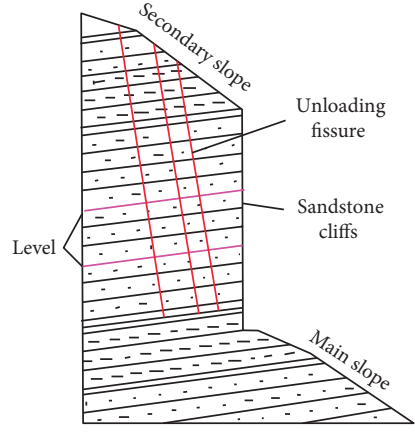

(a)

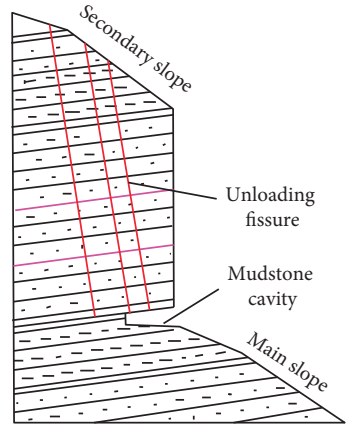

(b)

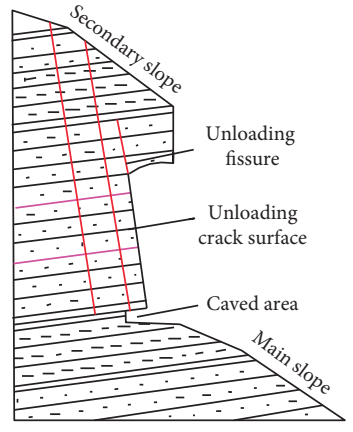

(c)

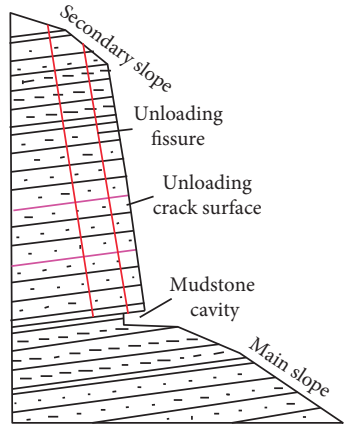

(d)

Figure 5: Collapse formation mode (the order of collapse is from (a) to (d)).

TABLE 2: The basic attitude of the dangerous rock mass.

\begin{tabular}{|c|c|c|c|c|c|c|}
\hline Number & $W 1$ & $W 2$ & $W 3$ & $W 4$ & W5 & W6 \\
\hline $\begin{array}{l}\text { General attitude } \\
\text { of the slope } \\
\text { surface }\end{array}$ & & & $\mathrm{N} 62^{\circ} \mathrm{W} / \mathrm{NE} \angle 84^{\circ}$ & & & \\
\hline Rock attitude & $\mathrm{N} 40^{\circ} \mathrm{W} / \mathrm{SW} \angle 8^{\circ}$ & $\mathrm{N} 60^{\circ} \mathrm{W} / \mathrm{SW} \angle 12^{\circ}$ & $\mathrm{N} 55^{\circ} \mathrm{W} / \mathrm{SW} \angle 10^{\circ}$ & $\mathrm{N} 54^{\circ} \mathrm{W} / \mathrm{SW} \angle 11^{\circ}$ & $\mathrm{N} 60^{\circ} \mathrm{W} / \mathrm{SW} \angle 13^{\circ}$ & $\mathrm{N} 55^{\circ} \mathrm{W} / \mathrm{SW} \angle 9^{\circ}$ \\
\hline $\begin{array}{ll}\text { Main joint } & J 1 \\
2\end{array}$ & $\begin{array}{c}\mathrm{N} 45^{\circ} \mathrm{W} / \mathrm{NE} \angle 89^{\circ} \\
\mathrm{N} 10^{\circ} \mathrm{E} / \mathrm{SE} \angle 86^{\circ}\end{array}$ & $\begin{array}{l}\mathrm{N} 79^{\circ} \mathrm{W} / \mathrm{NE} \angle 89^{\circ} \\
\mathrm{N} 82^{\circ} \mathrm{E} / \mathrm{NW} \angle 71^{\circ}\end{array}$ & $\begin{array}{l}\mathrm{N} 45^{\circ} \mathrm{W} / \mathrm{NE} \angle 80^{\circ} \\
\mathrm{N} 20^{\circ} \mathrm{E} / \mathrm{SE} \angle 85^{\circ}\end{array}$ & $\begin{array}{c}\mathrm{N} 40^{\circ} \mathrm{W} / \mathrm{NE} \angle 87^{\circ} \\
\mathrm{N} 10^{\circ} \mathrm{E} / \mathrm{SE} \angle 86^{\circ}\end{array}$ & $\begin{array}{l}\mathrm{N} 16^{\circ} \mathrm{W} / \mathrm{NE} \angle 88^{\circ} \\
\mathrm{N} 76^{\circ} \mathrm{E} / \mathrm{NW} \angle 87^{\circ}\end{array}$ & $\begin{array}{l}\mathrm{N} 20^{\circ} \mathrm{W} / \mathrm{NE} \angle 74^{\circ} \\
\mathrm{N} 80^{\circ} \mathrm{E} / \mathrm{NW} \angle 56^{\circ}\end{array}$ \\
\hline
\end{tabular}

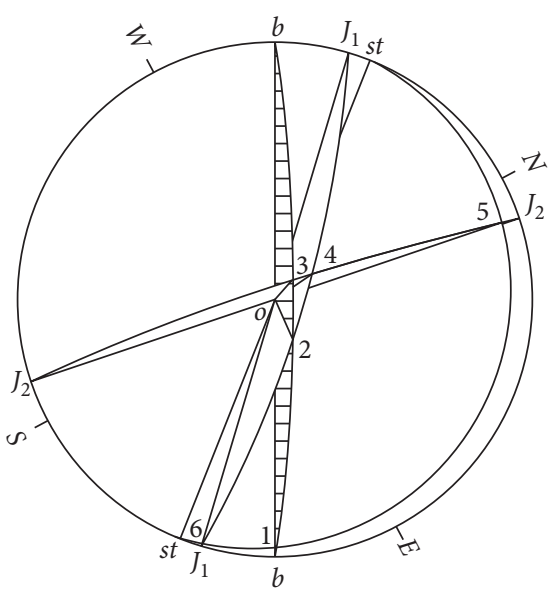

(a)

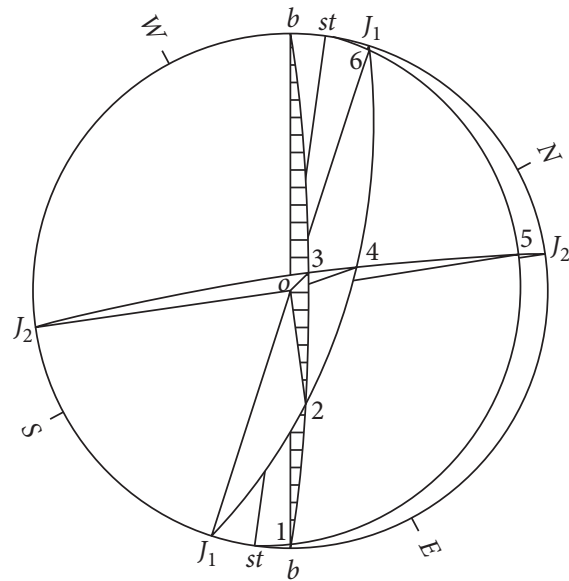

(c)

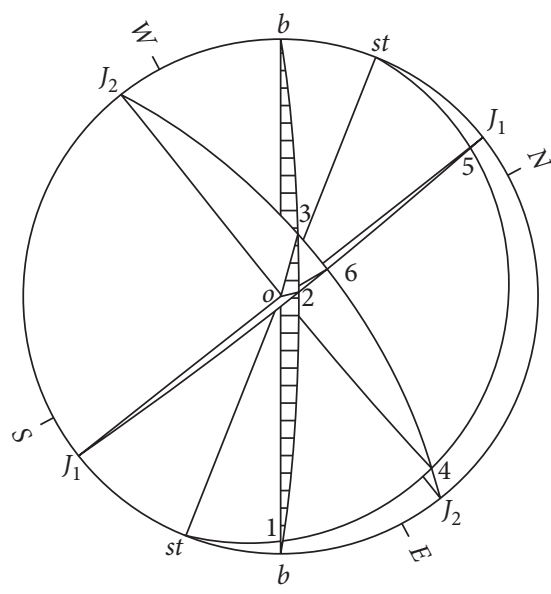

(b)

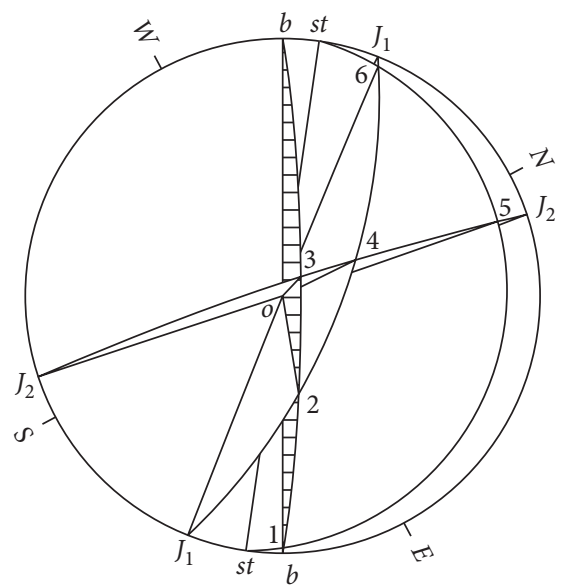

(d)

FIgURE 6: Continued. 


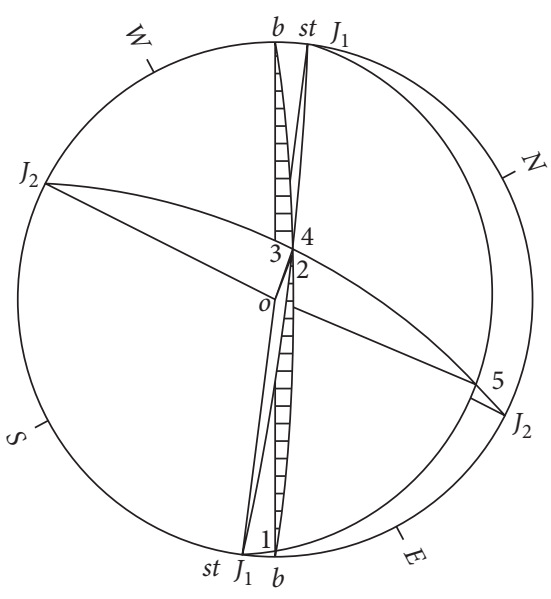

(e)

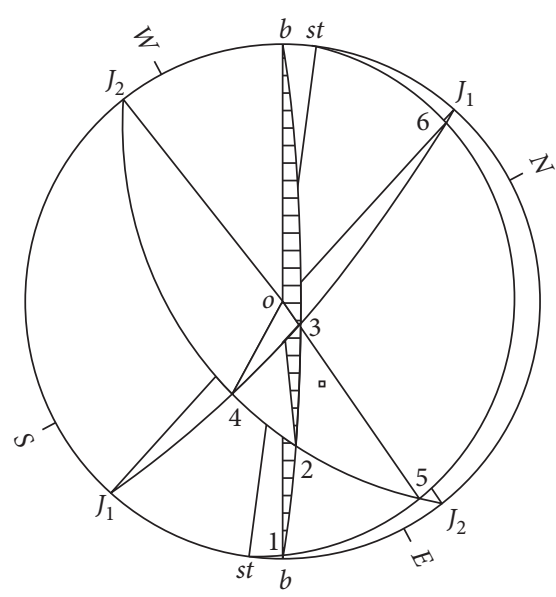

(f)

FiguRE 6: Analysis diagram of the stereographic projection. (a) W1. (b) W2. (c) W3. (d) W4. (e) W5. (f) W6.

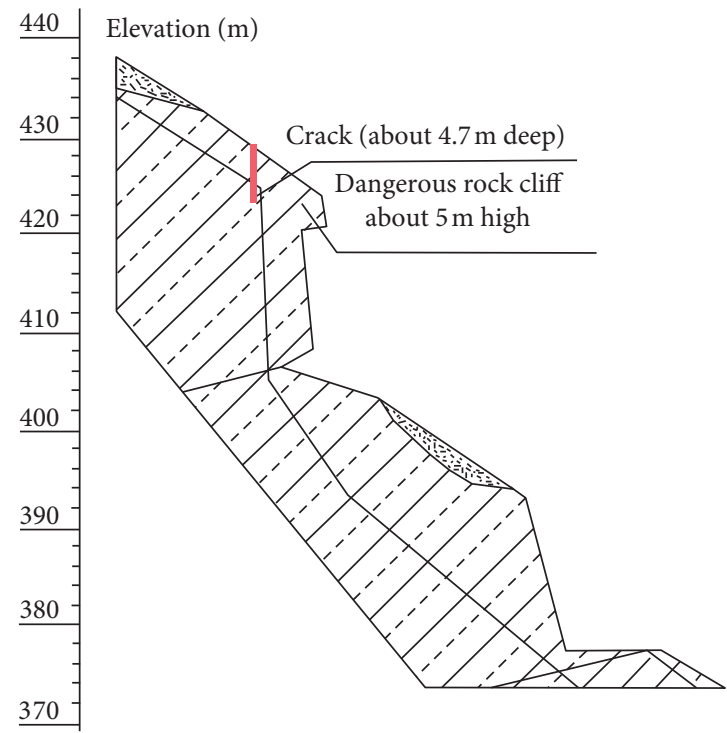

Figure 7: Falling-type dangerous rock mass of $W 1$.

$$
K=\frac{(W \cos \beta-P \sin \beta-Q) \tan \phi+C(H / \sin \beta)}{W \sin \beta+P \cos \beta}
$$

The above formulas (1)-(5) are about the calculation principle of the falling-type rock.

$$
\begin{aligned}
K & =\frac{M_{R}}{M_{O}}, \\
M_{O} & =W a+P h_{0}+Q\left(\frac{1}{3} \frac{e_{1}}{\sin \beta}+\frac{H-e}{\sin \beta}\right), \\
M_{R} & =\left[\sigma_{t}\right] \frac{H-e}{\sin \beta} \frac{H-e}{2 \sin \beta} \\
& =\frac{1}{2}\left[\sigma_{t}\right] \frac{(H-e)^{2}}{\sin ^{2} \beta} .
\end{aligned}
$$

The above formulas (6)-(8) are about the calculation principle of the tipping-type rock.

In the above formula, $W$ is the gravity of dangerous rock mass per unit length $(\mathrm{kN}) ; P$ is the horizontal seismic force $(\mathrm{kN})$ borne by dangerous rock mass per unit length; $Q$ is the hydrostatic pressure in the gap $(\mathrm{kN}) ; H$ is the vertical distance from the upper end of the edge fracture to the lower end of the incomplete segment $(\mathrm{m}) ; \beta$ is the dip angle $\left(^{\circ}\right)$ of the fracture surface; $c$ and $\varphi$, respectively, are the equivalent cohesive force $(\mathrm{kPa})$ and internal friction angle $\left({ }^{\circ}\right)$ of the fracture surface; $e$ is the pore depth $(\mathrm{m}) ; e_{1}$ is the pore water filling depth (m); $a$ is the horizontal distance between the gravity action point and the overturning point $(\mathrm{m}) ; h_{0}$ is the vertical distance between the seismic force and the overturning point $(\mathrm{m}) ;\left[\sigma_{t}\right]$ is the standard value of tensile strength of dangerous rock mass $(\mathrm{kPa}) ; M_{0}$ is the overturning moment $(\mathrm{kN} \cdot \mathrm{m})$; and $M_{R}$ is the antioverturning moment $(\mathrm{kN} \cdot \mathrm{m})$. 


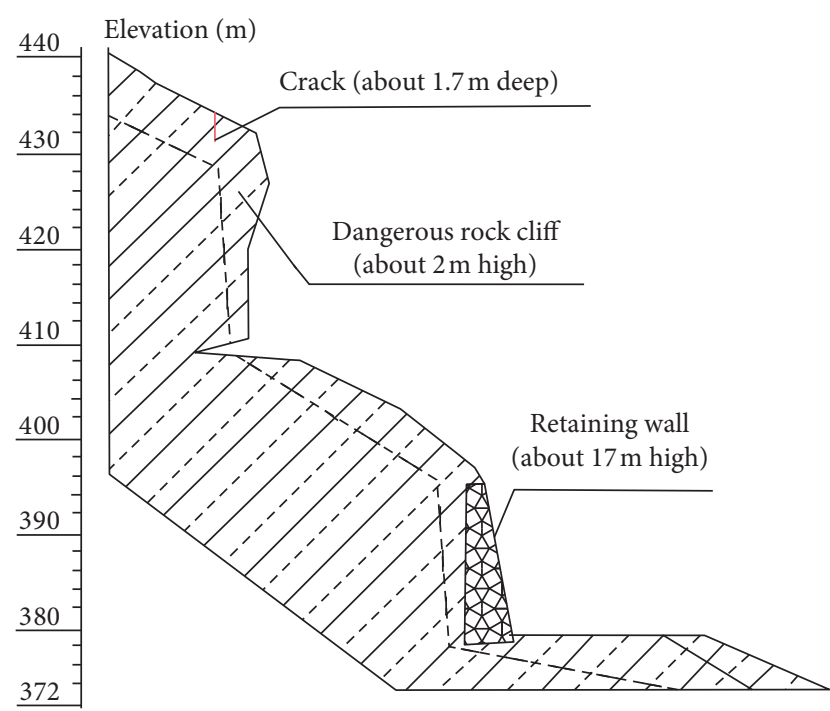

FIgURE 8: Falling-type dangerous rock mass of W3.

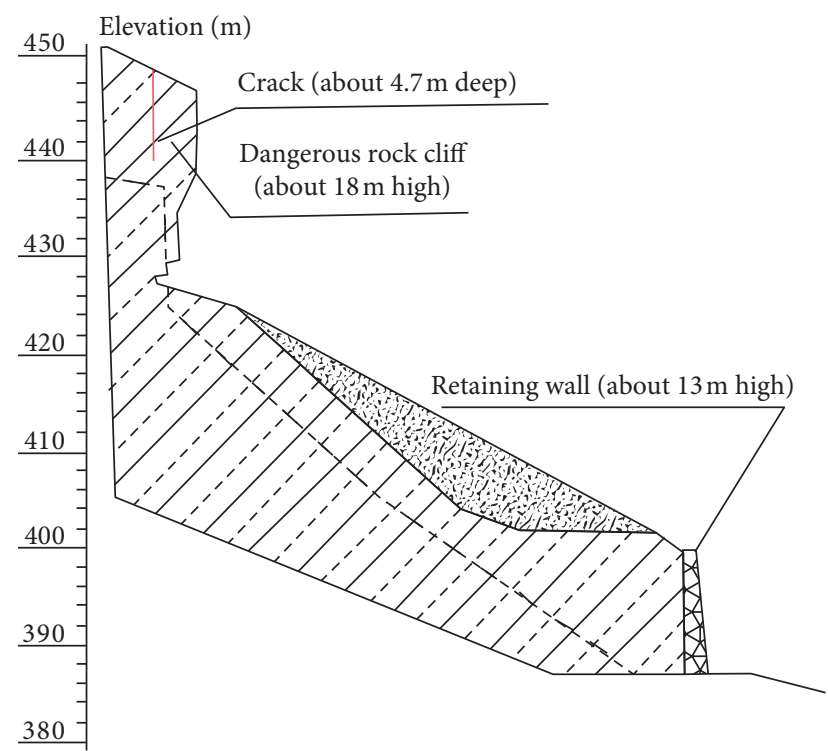

FIGURE 9: Falling-type dangerous rock mass of W4.

5.3.2. Load Combination. The failure modes of dangerous rock mass in the study area are tipping type and falling type, and the main influencing factors of dangerous rock activities are rainstorm. The basic seismic intensity in the exploration area is $7^{\circ}$. Considering the influence of the earthquake on dangerous rocks, the following three working conditions are selected to evaluate the stability of dangerous rocks:

Working condition I: self-weight (natural)

Working condition II: self-weight + fissure water pressure (rainstorm)

Working condition III: self-weight + fissure water pressure (rainstorm) + earthquake force

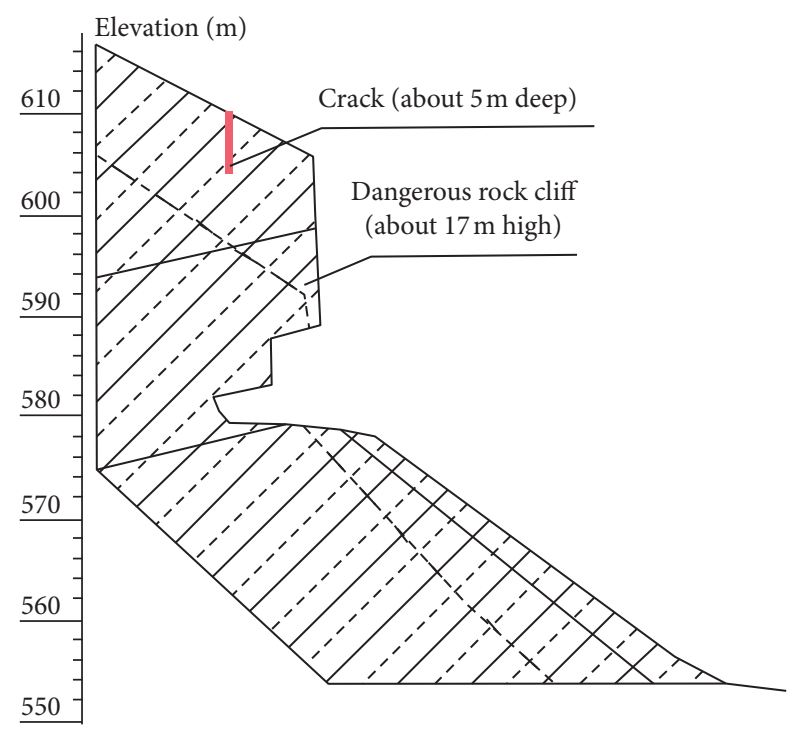

FIGURE 10: Falling-type dangerous rock mass of W6.

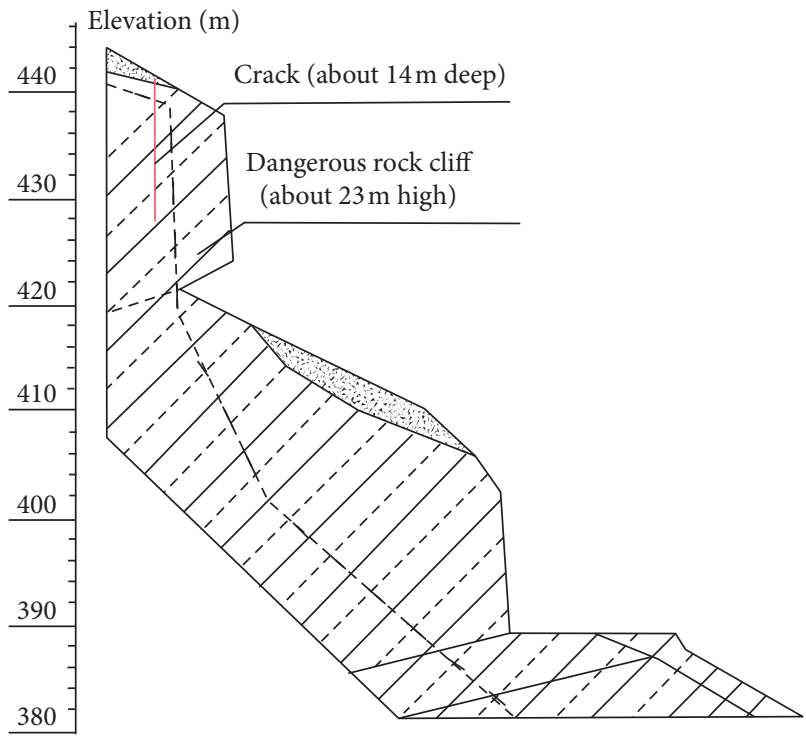

FIgURE 11: Tipping-type dangerous rock mass of $W 2$.

5.3.3. Calculation Parameters of Dangerous Rocks. The dangerous rock mass in the study area is mainly metamorphic sandstone. Suggested values and characteristic parameters of physical and mechanical parameters of the rock mass are shown in Tables 3-5.

\subsection{Stability Assessment of Dangerous Rock Mass}

5.4.1. Stability Discrimination Basis of Dangerous Rock Mass. Refer to the Landslide Industry Code in China "Specification of geological investigation for landslide stabilization (DZ/ T0218-2006)." The stable state of dangerous rock mass can be divided into four states: stable, basically stable, understable, and unstable. The specific determination basis is shown in Table 6. 


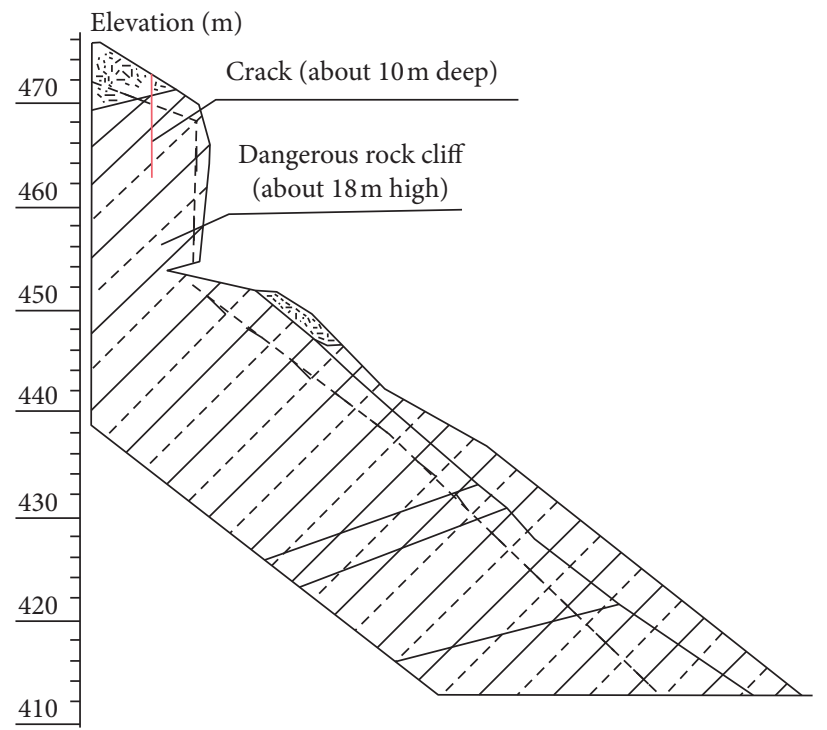

FIgURE 12: Tipping-type dangerous rock mass of W5.

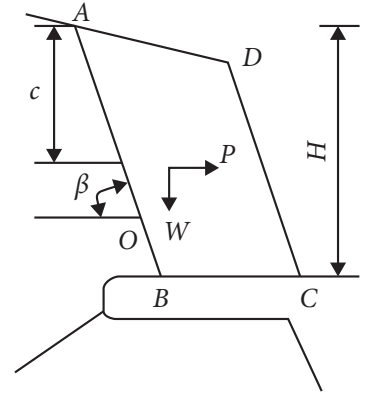

FIgURE 13: Calculation model for the unstable falling-type rock.

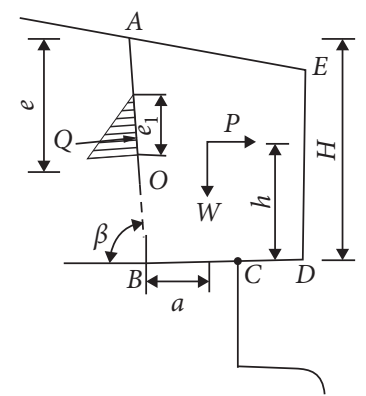

FIGURE 14: Calculation model for the unstable tipping-type rock.

TABLE 3: Suggested parameter values.

\begin{tabular}{lc}
\hline Physical and mechanical parameter & Suggested values \\
\hline Natural gravity $\left(\mathrm{kN} / \mathrm{m}^{3}\right)$ & 2.00 \\
Saturated unit weight $\left(\mathrm{kN} / \mathrm{m}^{3}\right)$ & 25.50 \\
Natural compressive strength $(\mathrm{MPa})$ & 25.60 \\
Saturated compressive strength $(\mathrm{MPa})$ & 18.80 \\
Natural tensile strength $(\mathrm{MPa})$ & 1.60 \\
Saturated tensile strength $(\mathrm{MPa})$ & 1.52 \\
\hline
\end{tabular}

TABLE 4: Characteristic parameters of falling-type dangerous rocks.

\begin{tabular}{|c|c|c|c|c|}
\hline $\begin{array}{l}\text { Dangerous rock mass number } \\
\text { Characteristic parameters }\end{array}$ & $W 1$ & $W 3$ & $W 4$ & W6 \\
\hline per unit length $(t)$ & 50.6 & 5.4 & 58.0 & 215.0 \\
\hline Dip angle of the fracture surface $\left({ }^{\circ}\right)$ & 89.0 & 80.0 & 87.0 & 74.0 \\
\hline $\begin{array}{l}\text { Cohesive force of the rock mass } \\
(\mathrm{kPa})\end{array}$ & 700.0 & 700.0 & 700.0 & 700.0 \\
\hline $\begin{array}{l}\text { Internal friction angle of the rock } \\
\text { mass }\left({ }^{\circ}\right)\end{array}$ & 31.9 & 31 & 31.9 & 310 \\
\hline $\mathrm{n}$ of structural planes $(\mathrm{kPa})$ & 70.0 & 70.0 & 70.0 & 70.0 \\
\hline ) & 28 & 28 & 28 & 28 \\
\hline esion $(\mathrm{kPa})$ & 07.8 & 164.5 & 162.7 & 107.1 \\
\hline $\begin{array}{l}\text { Equivalent angle of internal } \\
\text { friction }\left({ }^{\circ}\right)\end{array}$ & 28 & 28 & 28.6 & 28 \\
\hline e force $(\mathrm{kN})$ & 60.7 & 42.5 & 309.6 & 258.0 \\
\hline & -51.9 & 19.64 & -174.2 & 344.6 \\
\hline Tangential fo & 506.9 & 356.0 & 2592.6 & 2137.8 \\
\hline
\end{tabular}

TABle 5: Characteristic parameters of tipping-type dangerous rocks.

\begin{tabular}{lcc}
\hline $\begin{array}{l}\text { Dangerous rock mass number } \\
\text { Characteristic parameters }\end{array}$ & $W 2$ & $W 5$ \\
\hline Weight per unit length $(\mathrm{t})$ & 465.5 & 364.3 \\
Dip angle of the fracture surface $\left(^{\circ}\right)$ & 89.0 & 83.0 \\
Hydrostatic pressure $(\mathrm{kN})$ & 106.7 & 54.8 \\
Earthquake force $(\mathrm{kN})$ & 558.6 & 437.2 \\
{$\left[\sigma_{t}\right](\mathrm{kPa})$} & 390.8 & 390.8 \\
$H-e(\mathrm{~m})$ & 9.0 & 8.0 \\
Overturning moment & 7550.6 & $11,723.9$ \\
Resistance moment & $15,832.2$ & $12,694.1$ \\
\hline
\end{tabular}

TABLE 6: Criteria for the stability evaluation of dangerous rocks.

\begin{tabular}{lcccc}
\hline \multirow{2}{*}{ Failure mode } & \multicolumn{4}{c}{ Stable state } \\
& Unstable & Understable & Basically stable & Stable \\
\hline Falling type & $K<1.0$ & $1.0 \leq K<1.5$ & $1.5 \leq K<1.8$ & $K \geq 1.8$ \\
Tipping type & $K<1.0$ & $1.0 \leq K<1.3$ & $1.3 \leq K<1.5$ & $K \geq 1.5$ \\
\hline
\end{tabular}


TABLE 7: Calculation results of dangerous rock stability.

\begin{tabular}{|c|c|c|c|c|c|}
\hline Failure mode & Dangerous rock number & Working condition & Stability factor & Stable state & Hazard probability (\%) \\
\hline \multirow{12}{*}{ Falling type } & \multirow{3}{*}{$W 1$} & I & 1.075 & Understable & 20.4 \\
\hline & & II & 0.950 & Unstable & 30.8 \\
\hline & & III & 0.928 & Unstable & 32.7 \\
\hline & \multirow{3}{*}{$W 3$} & I & 1.024 & Understable & 24.7 \\
\hline & & II & 0.980 & Unstable & 28.3 \\
\hline & & III & 0.953 & Unstable & 30.6 \\
\hline & \multirow{3}{*}{$W 4$} & I & 1.101 & Understable & 18.3 \\
\hline & & II & 0.953 & Unstable & 30.6 \\
\hline & & III & 0.909 & Unstable & 34.3 \\
\hline & \multirow{3}{*}{ W6 } & I & 1.006 & Understable & 26.2 \\
\hline & & II & 0.863 & Unstable & 38.1 \\
\hline & & III & 0.833 & Unstable & 40.6 \\
\hline \multirow{6}{*}{ Tipping type } & \multirow{3}{*}{$W 2$} & I & 1.026 & Understable & 24.5 \\
\hline & & II & 0.907 & Unstable & 34.4 \\
\hline & & III & 0.866 & Unstable & 37.8 \\
\hline & \multirow{3}{*}{ W5 } & I & 1.168 & Understable & 12.7 \\
\hline & & II & 1.085 & Understable & 19.6 \\
\hline & & III & 1.040 & Understable & 23.3 \\
\hline
\end{tabular}

5.4.2. Safety Analysis Results. Hazard probability reflects the general relationship between the disaster rate and the stability coefficient under different working conditions. The calculation formula adopts the empirical formula proposed by Zhang [27] and Deng [28].

$$
P=1.1-\frac{k}{1.2}
$$

In the above formula (9), $P$ is the hazard probability of the disaster; $K$ is the stability coefficient of dangerous rock mass. When $K \geq 1.2, K=1.2$ is taken. The calculation results of dangerous rock mass under different working conditions are shown in Table 7.

\section{Conclusions}

In this paper, six groups of dangerous rock mass with overhanging slope in Puerdu Town, Yanjin County, Zhaotong City, Yunnan Province, China, were taken as the research objects. Field investigation was conducted to analyze the development characteristics of dangerous rock mass and define its failure and instability modes. According to the characteristics of dangerous rock mass, a simplified geological model is established. The influence of dead weight, rainstorm, and earthquake on dangerous rock mass is considered reasonably, and the stability state of dangerous rock mass under different working conditions of the overhanging slope is objectively reflected. The stability coefficient of dangerous rock mass under different working conditions is calculated by the limit equilibrium method, and the hazard probability is estimated by the empirical formula. The main conclusions are as follows:

(1) According to the results of the engineering geological survey, the joints of dangerous rock mass ( $W 1, W 2$, $W 3, W 4, W 5$, and $W 6)$ in the study area are obviously developed, with good hanging conditions and serious potential threats.

(2) The failure mode of dangerous rock mass ( $W 1, W 3$, $W 4$, and W6) in the study area is falling type, and the failure mode of dangerous rock mass $W 2$ and $W 5$ is tipping type.

(3) In dangerous rock mass ( $W 1, W 2, W 3, W 4, W 5$, and W6), under condition I, stability coefficient $K=1.006-1.101$, for the understable state, and the hazard probability is $18.3-26.2 \%$; under condition II, stability coefficient $K=0.863-1.168$, which is an unstable state, and the hazard probability is 19.6-38.1\%; under condition III, stability coefficient $K=0.833-1.040$, which is an understable state, and the hazard probability is $23.3-40.6 \%$. In a word, the dangerous rock mass including $W 1, W 2, W 3, W 4$, $W 5$, and $W 6$ is mostly in the understable state. Under the conditions of rainstorm and earthquake, the stability coefficient decreases, and the hazard probability increases. Therefore, monitoring should be strengthened.

\section{Data Availability}

The data used to support the findings of this study are included within the article.

\section{Conflicts of Interest}

The authors declare that there are no conflicts of interest regarding the publication of this paper.

\section{Acknowledgments}

This study was sponsored by the Talent Development Program of Kunming University of Science and Technology 
(nos. KKSY201504022 and KKSY201767034) and Kunming Prospecting Design Institute of China Nonferrous Metal Industry Co., Ltd. (Risk Assessment Method of Dangerous Rock High Slope in Northeast Yunnan Based on Engineering Geological Evolution).

\section{References}

[1] H. Chen and X. Qin, "Status quo and trend of unstable rock stability analysis," Journal of Chongqing Jiaotong University (Natural Science Edition), vol. 37, no. 10, pp. 49-60, 2018.

[2] J. Wang, "Design of collapse control scheme for dangerous rock in overhanging slope," Communications Science and Technology Heilongjiang, vol. 33, no. 6, pp. 49-50, 2010.

[3] $\mathrm{Hu} \mathrm{Gu}$, "Risk assessment of earthquake-induced collapse disaster in Jiuzhaigou scenic area," Chengdu University of Technology, 2019.

[4] C. Li, T. Kang, X. Li, and L. Li, "Theoretical investigation of the sliding instability and caving depth of coal wall workface based on the bishop strip method," Advances in Civil Engineering, vol. 2019, no. 1, 8 pages, 2019.

[5] K. Mithun, M. F. A. Ayad, and M. Ismail, "Glacier changes monitoring in Bhutan high imalaya using remote sensing technology," Environmental Engineering Research, vol. 26, no. 1, pp. 38-50, 2021.

[6] H. F. Li, G. X. Zhang, T. Huang, and Q. J. Zhou, "Stability analysis of dangerous rocks on the slope of a hydropower station," Applied Mechanics and Materials, vol. 405-408, pp. 621-629, 2013.

[7] L. Wang, Y. Yin, B. Huang, and Z. Dai, "Damage evolution and stability analysis of the Jianchuandong dangerous rock mass in the three Gorges reservoir area," Engineering Geology, vol. 265, Article ID 105439, 2020.

[8] P. Li, "Analysis of collapse deformation mechanism and prevention measures of Shiwei rock in Zhangkou, Chongqing," Modern Mining, vol. 36, no. 2, pp. 160-163+169, 2020.

[9] J. Dong, G. Xu, Z. Li et al., "Classification and risk rating assessment of hazard sources in surrounding slope of Busigou hydropower project," Journal of Engineering Geology, vol. 20, no. 5, pp. 760-767, 2012.

[10] Z. Kuang, "Study on characteristics, deformation mechanisms and control of dangerous rock and rock fall in central area of Chongqing city," Journal of Geological Hazards and Prevention in China, vol. 6, no. 3, pp. 51-56, 1995.

[11] R. HuangR. Deng et al., Simulation of Whole Process of Material Movement in Overhanging Slope, Chengdu University of Science and Technology Press, Chengdu, Sichuan, China, 1993.

[12] Q. Zhang, G. Peng, S. Fu et al., "System identifucation of deformation-failure for the dangerous rock body of Lianzi cliff," Chinese Journal of Rock Mechanics and Engineering, vol. 17, no. 5, pp. 66-73, 1998.

[13] Z. Li, W. Xiang, and M. Zhang, "Study on stability analysis and treatment plan of sliding dangerous rock mass," Resource Environment and Engineering, vol. 34, no. S2, pp. 83-89, 2020.

[14] L. Zhang, D. Wang, G. Li, J. Dong, and J. Zhang, "Stability analysis and reliability evaluation in cataclastic loose rock mass blocks," Advances in Civil Engineering, vol. 2021, Article ID 5314937, 2020.

[15] H. Tao, G. Xu, J. Meng, R. Ma, and J. Dong, "Stability assessment of high and steep cutting rock slopes with the SSPC method," Advances in Civil Engineering, vol. 2021, Article ID 8889526, 2021.
[16] Y. Gong, "Study on the stability of dangerous rock based on limit equilibrium method and fracture mechanics method," Gansu Water Resources and Hydropower Technology, vol. 54, no. 9, pp. $48-51+65,2018$.

[17] S. Xiao, "Stability analysis of dangerous rock based on limit equilibrium method," Water Resources \& Hydropower of Northeast China, vol. 37, no. 12, pp. 52-72, 2019.

[18] Y. Chen, "Stability analysis of slump dangerous rock mass," Express Water Resources \& Hydropower Information, vol. 40, no. 7, pp. 23-26, 2019.

[19] X. Li, P. Chen, and H. Shi, "Evaluating stability and its reliability of dangerous rock at abandoned Longsi mine in Jiaozuo," Journal of Geological Hazards and Environment Preservation, vol. 26, no. 3, pp. 92-97, 2015.

[20] M. Zhao and X. Bu, "Analysis the application of rigid body limit equilibrium method to dangerous rock mass stability," Journal of Changchun Institute of Technology (Natural Science Edition), vol. 14, no. 3, pp. 75-78+103, 2013.

[21] B. Liu, Z. Pan, and J. Zheng, "Development characteristics and stability analysis of karst dangerous rock mass in Guilin city," Journal of Natural Disasters, vol. 22, no. 1, pp. 183-189, 2013.

[22] Y. Zhang, W. Zhou, Z. Wu, F. Guo, and X. Zheng, "The development status of 3D geological modeling technology and modeling instances," Journal of East China University of Technology (Social Science Edition), vol. 32, no. 3, pp. 403-409, 2013.

[23] S. Doug and W. Andrea, "A critical review of rock slope failure mechanisms: the importance of structural geology," Journal of Structural Geology, vol. 74, pp. 1-23, 2015.

[24] W. Liu, "Study on stability, movement characteristics and countermeasures of potential unstable rock mass in highsteep slope," Chengdu University of Technology, 2008.

[25] H. Chen, H. Tang, and R. Wang, "Calculation method of stability for unstable rock and application to the three gorges reservoir," Rock Mechanics and Engineering, vol. 23, no. 4, pp. 614-619, 2004.

[26] H. Chen, X. Xiang, H. Tang et al., "A massive development mechanism and countermeasures for perilous rocks in the Three Gorges Reservoir area of P. R. China: the example of the Taibaiyan cliff at Wanzhou," Journal of Chongqing University, vol. 31, no. 10, pp. 1178-1184, 2008.

[27] Y. Zhang, Study on the Risk Analysis of the Fenghuangshan's Landslides in Yan'an, Chang'an University, Yanan, China, 2008.

[28] G. Deng, Study on Risk Assessment of Loess Landslide Disaster: A Case Study of Loess Landslide in Baota District, Yanan, Chang'an University, Shaanxi, China, 2008. 